\title{
La agroproducción sustentable desde la perspectiva del desarrollo endógeno
}

\section{Sustainable agro-production from the perspective of endogenous development}

\author{
Manuel Emilio Milla Pino ${ }^{1 *}$ (D), Danny Alberto Villegas Rivas ${ }^{2}$ (D), Ricardo Ángel Shimabuku Ysa ${ }^{3} \mathbb{D}$, River Chávez Santos ${ }^{4}$ (D)
}

\section{RESUMEN}

El desarrollo endógeno está vinculado al reconocimiento de las potencialidades que poseen las comunidades y en función de ellos, concebir y ejecutar proyectos agroproductivos en el marco de la sustentabilidad, que sean ambientalmente benignos, socialmente aceptables y económicamente viables. Esto permitirá el desarrollo de los individuos y de las comunidades, estableciendo nexos que garanticen la mejora de la calidad de vida y el fortalecimiento del tejido social, a través de la formulación, evaluación programación y control de proyectos sociocomunitarios, socio-productivos y socio-integradores.

Palabras clave: agroproducción, sustentable, endógeno.

\section{ABSTRACT}

Endogenous development is linked to the recognition of the potentials that communities possess and, based on them, conceiving and executing agro-productive projects within the framework of sustainability, which are environmentally benign, socially acceptable and economically viable. This will allow the development of individuals and communities, establishing links that guarantee the improvement of the quality of life and the strengthening of the social fabric, through the formulation, evaluation, programming and control of sociocommunity, socio-productive and partner-integrators.

Key words: agroproduction, sustainable, endogenous.

\footnotetext{
${ }^{1}$ Universidad Nacional de Jaén, Facultad de Ingeniería Civil, Perú

${ }^{2}$ Universidad Nacional de Jaén, Facultad de Ingeniería Forestal y Ambiental, Perú

${ }^{3}$ Universidad Nacional de Jaén, Facultad de Ingeniería Mecánica y Eléctrica, Perú

${ }^{4}$ Universidad Nacional Toribio Rodríguez de Mendoza, Facultad de Ciencias Económicas y Administrativas, Perú

"Autor de Correspondencia: manuel.milla@unj.edu.pe
} 


\section{INTRODUCCIÓN}

El proceso agroproductivo requiere cumplir con los siguientes fundamentos:

a. Concepción y ejecución que garantice el menor daño posible al ambiente, es decir, que sea ambientalmente benigno.

b. Visión que fortalezca la incorporación del entorno al trabajo colectivo, lo que permitiría clasificarlo como socialmente aceptable.

c. Constituir una fuente de ingresos para la subsistencia y estabilidad familiar, aspecto que lo convierte en económicamente viable.

Este escenario es una fiel evidencia del carácter sustentable de la agroproducción, el cual exige un exhaustivo diagnóstico de las potencialidades naturales, físicas y humanas en aras de considerarlas al momento de definir los elementos claves del proceso para garantizar un desarrollo eficaz y eficiente de las acciones, y estimular la esencia endógena como mecanismo de consolidación y mejora de la calidad de vida de la sociedad.

El desarrollo desde adentro con énfasis en el impulso de la trilogía ambiental - social - económica viene hacer una estrategia lógica y racional para generar una agroproducción sustentable (Leff, 2008).

\section{SISTEMATIZACIÓN DEL DESARROLLO ENDÓGENO}

Es la vinculación y secuencialidad de las acciones requeridas para promover estrategias de desarrollo, en la cual las potencialidades internas de las comunidades sean el eje que direccione el sistema agroproductivo. Los elementos constitutivos del sistema son:

\section{Diagnóstico}

Consiste en una revisión detallada de los elementos que conforman la comunidad productiva, precisando la potencialidad actual y futura de cada uno de ellos (Martíy Asensio, 2003).

\section{Potencialidades}

Es la identificación de los factores de mayor potencialidad que constituyen la base productiva de la comunidad y que permitirá caracterizar las opciones de pro- yectos a desarrollar con una mirada en el futuro (Martí y Asensio, 2003).

\section{Alternativas de producción}

Es la fase donde se definen los mecanismos de producción suceptibles de ser implementados y que garantizarán el fortalecimiento y el desarrollo de proyectos socio-comunitarios y/o socio-productivos y/o sociointegradores (Martí y Asensio, 2003).

\section{Sustentabilidad}

Constituye la fase de revisión exhaustiva del cumplimiento de los criterios ambientalmente benigno, socialmente aceptable y económicamente viable de los proyectos y fundamentado en ello seleccionar los que se van a emprender (Martí y Asensio, 2003).

\section{Calidad de vida}

Se refiere a los aspectos inherentes a la contribución y aportes que los proyectos a desarrollar harán a la mejora de la calidad de vida de la sociedad al cual están dirigidos (Martí y Asensio, 2003).

\section{SUSTENTABILIDAD AGROPRODUCTIVA}

El proceso agroproductivo debe enmarcarse dentro de una estructura que brinde satisfacción a la sociedad y que garantice viabilidad en el desarrollo de las futuras generaciones, es por ello que a continuación se especifican los siguientes elementos:

\section{Satisfacción ambiental}

Las futuras generaciones requieren contar con un ambiente que les permita vivir en armonía y eso debemos garantizarlo con la implementación de procesos productivos que causen el menor daño posible al ambiente (Martí y Asensio, 2003).

\section{Satisfacción social}

La sociedad exige ser incorporada masivamente a los procesos productivos, de tal manera que estos deben estar orientados hacia las capacidades, habilidades y destrezas con que cuenta la comunidad (Martí y Asensio, 2003).

\section{Satisfacción económica}

La vida cotidiana requiere de elementos económicos para seguir adelante, esto hace necesario la ejecución de proyectos que sean viables económicamente y que 
generen unos márgenes de ganancia que permitan su estabilidad y consolidación, contribuyendo así con la satisfacción de las necesidades prioritarias de la sociedad (Martí y Asensio, 2003).

\section{DESARROLLO HUMANO}

La selección y ejecución de proyectos generados a partir de la interacción con la sociedad, se convierte en el pilar fundamental para mejorar los índices de desarrollo humano, ya que involucrar a la sociedad en el diagnóstico de la problemática a ser abordada en los proyectos, estimula y fortalece la vinculación entre el investigador, el problema estudiado y la sociedad. Entre los tipos de proyectos que impulsan el desarrollo humano, se pueden mencionar:

\section{Sociocomunitarios}

Son proyectos que generan beneficios colectivos y se orientan hacia la consolidación de las comunidades a través del fortalecimiento de las relaciones sociales, ya que crean espacios comunes para el esparcimiento y compartir (Martí y Asensio, 2003).

\section{Socioproductivos}

Son proyectos que permiten la obtención de beneficios económicos de carácter colectivos y tienen su fundamento en los criterios de sustentabilidad (Martí y Asensio, 2003).

\section{Sociointegradores}

Son proyectos en los que distintas áreas del conocimiento, género y grupos etarios convergen para alcanzar un objetivo colectivo, y tienen como premisa básica el intercambio de saberes (Martí y Asensio, 2003).

\section{EMPRENDIMIENTO E INNOVACIÓN}

Esta referido a explorar nuevas ideas y conceptos para la ejecución de tareas que permitan alcanzar los objetivos con una visión en tiempo y espacio que rompa con los esquemas tradicionales de producción (Martí y Asensio, 2003).

\section{Emprendimiento}

Es necesario una búsqueda minuciosa de nuevas alternativas productivas basadas en el talento natural y espontáneo que tienen los miembros de las comunida- des, los cuales han sido fortalecidos por la experiencia acumulada a lo largo de los años, pero que no ha recibido la oportunidad de ser desarrollada (Martí y Asensio, 2003).

\section{Innovación}

El fortalecimiento del tejido social se logra a través de la exitosa aplicación de las ideas generadas a partir del emprendimiento, esto indica que la innovación es el proceso que permitirá que el espíritu emprendedor rinda sus frutos (Martí y Asensio, 2003).

\section{EPISTEMOLOGÍA DELDESARROLLO}

En virtud de que desde el punto de vista epistemológico se da una relación entre el sujeto y objeto de estudio, la concepción y ejecución de los proyectos agroproductivos se enmarcan dentro de las pautas del método cientifico con el propósito de generar un conocimiento de carácter objetivo en estricta vinculación con el entorno (PNUMA, 2006).

Se refleja entonces, un mecanismo que va desde la actuación individual hacia las acciones estructurales que se utilizan para elaborar el conocimiento. En tal sentido, se estudia el grado de asociación entre las creencias que posee el individuo y el conocimiento que emana de la puesta en marcha de sus proyectos de cara al desarrollo y el fortalecimiento del tejido social (Jaula, 2003).

\section{REFLEXIÓN}

En el contexto de la epistemología se reconoce las capacidades de los individuos para elaborar conocimientos, internalizando la dinámica permanente que los rodea, como instrumento prioritario para su exitosa inserción en la sociedad. De allí, que sea de vital importancia la incorporación de los individuos al proceso agroproductivo y garantizar las condiciones para el establecimiento de una sinergia entre individuo - sociedad en pro del desarrollo humano.

\section{REFERENCIAS BIBLIOGRÁFICAS}

Martí, I y J. M. Asensio. 2003. Diccionario enciclopédico de educación. Barcelona (España): Edi- 


\section{torial CEAC.}

Jaula, J. A. 2003. "Sobre el reto de la universidad ante la protección del medio ambiente y el desarrollo sustentable." Guayana Sustentable 4.

Leff, E. 2008. Discursos Sustentables. Ciudad de México (México): Editores Siglo XXI.

PNUMA (Programa de las Naciones Unidas para el Medio Ambiente). 2006. Manifiesto por la vida. Ciudad de México (México): PNUMA 